\title{
The Impact of Electrical Vehicles on Sustainability: Jordan as a Case Study
}

\author{
MALAK M. S. \\ Obuda University, Budapest, Hungary., malak.shatnawi@phd.uni-obuda.hu
}

Abstract. The Global concern is moving toward making a revolution in favor of exploitation of renewable energy in order to improve environment conditions, limit emissions and minimizes consumption of non-renewable resources within the planet. In this context, it is necessary to focus on the transport sector as it contributes of at least $30 \%$ of the total primary energy consumption. Therefore, a set of rules must be developed to maintain economic, environmental and social sustainability to address the problems so as not to increase their severity and these cannot be done unless there are joint measures and regulations from governments, companies, manufacturers and users.

Unfortunately, the Jordanian transport system mostly depend on the individual transport which supported by cars, and that because of the weak role played by the public transport sector, especially at the capital, Amman.

Buying hybrid cars (internal combustion engine + electric motor) and Electrical Vehicles (EV), in the past few years in Jordan is increasing, which is compatible with the global trend to use Electrical Vehicles (EV) instead of Internal Combustion Engine vehicles (ICE) powered by fossil fuels, this issue will have a direct and indirect impact on gas stations companies, also it will have direct impact on labor sector and the current car industry since electric charging stations as well as EV manufacturing is not labor intensive

The main purpose of the study is to show how much it is necessary now to start theoretical assumptions through studying the expected annual increase in passenger cars and its impact on sustainability and predicting the future fuel consumption and emissions and compare them with the base situation.

Keywords: Electric Vehicles, Sustainability, Energy Consumption, Environment.

\section{Introduction}

Based on the fact that energy consumption by transportation sector particularly for the part related to road transport will continue to increase within time, this require more concern to be given for energy efficiency in order to reduce its negative impact.

Electric vehicles (EVs) represent an innovation in automotive technology whereby the power train of the vehicle operates partly or solely from electricity stored in an on-board battery [1].

It is expected that in the next 10 to 20 years the electric (EV) will be the solution, these cars are becoming global affair because of its importance in reducing fuel consumption, $\mathrm{CO} 2$ and other (NOx, SOx and PM pollutants) emissions as well as reducing all types of traffic noise.

Introducing alternative fuels and efficient engine technologies is a global issue; (European Commission (EC)) main target by the year 2020 is to rely on renewable energy resources for its road vehicles. The Europe primary sources for obtaining electricity rely heavily on coal, oil, gas and nuclear energy, and 
the goal should be looking for energy sources used (renewable and/or non-fossil sources) and investing in better management and technologies to reduce pollution. These and more will have direct and indirect impact on transportation infrastructure and its environmental dimensions of sustainability for generations to come.

However, EVs still have some drawbacks that need to be fixed, for example the ambiguity of the manufacturing situations and the process of battery recycling at the battery expireslife as well as the recharging and powered source, which mostly obtained from non-environmental sources making the main disadvantages issues that must be taken into consideration, in addition to that the EVs must be powered with electricity (to charge battery), which is obtained from non-environmental sources.

There are serious limitations regarding the EVs battery capacity, the driving range and charging time which will cause changes in the style of fuel refilling (refuelling) /electric charging, to be compatible with the period that required for refuelling / charging and the frequently number of visits, not to mention the concern of indirect and direct environmental effects in the manufacturing ,operating and recycling of electric motor batteries through the life cycle of the cradle to the grave. This issue will have a direct impact on gas station that will affect the revenue of such companies; also it will have a direct impact on labour since electric charging station is not a labour intensive in addition to the adverse impacts on the current car industry because EV manufacturing is not a labor intensive industry.

This paper will consist from the following sections;

first section is literature review regarding the effects of electric vehicles and Future of Electrical Cars EV related to Emissions, the second section analysis of Jordan transport sector, the third Section explains the methodology of research, the fourth section will provide results of analysis from environmental perspective, and last section is conclusions, future prediction and recommendations.

\section{Literature Review}

It is expected that in the next 10 to 20 years the the smart mobility modes including electric vehicles (EV) will be the solution for transportation sustainability, these modes will become the global affair because of its importance in reducing the environmental, economic and social negative impact.

Sustainability in general is gaining balance between three main pillars "delicate balance between the economic, environmental and social health of a community" [2]. However, sustainability from transportation perspective as reviewed in most literatures is the future capacity to enhance mobility needs of a society to be less harmful for the environment and does not violate the mobility needs for generations to come. The detailed impact of sustainable transportation on each pillar was summarized in (Table 1.).

\begin{tabular}{|l|l|l|}
\hline Economic & Environmental & Social \\
\hline Traffic congestion & Air pollution & Equity / Fairness \\
Infrastructure costs & Climate change & Impacts on mobility disadvan- \\
Consumer costs & Noise and water pollution & taged \\
Mobility barriers & Habitat loss & Human health impacts \\
Accident damages & Hydrologic impacts & Community cohesion \\
Depletion of Non-Renewable & Depletion of Non-Renewable & Community liveability \\
Resources & Resources & Aesthetics \\
\hline
\end{tabular}

Table 1. The impact of sustainable transportation on each pillar [3]. 
Environment issues such as greenhouse gas (GHG) emissions and fossil fuels are very severe matter that cannot be ignored because it will leave the world with serious problems leading to global uncontrolled dangerous, so the main concern must be to limit such emissions since the energy consumption by transportation sector more than $30 \%$ of the total primary energy consumption which require serious actions in order to reduce the negative impact in all fields.

Introducing alternative fuels and efficient engine technologies is global issue (European Commission (EC)), by the year 2020 the main target is using renewable energy resources in road vehicles. hybrid vehicles (internal combustion engine + electric motor) will lead to lower emissions.

Hybrid and electric vehicles (EV) technologies in mobility seems to be a reasonable solution for passenger cars. "For example, "the CO2 emission of the Toyota Prius hybrid vehicle is $20 \%$ lower than emission of a similar car that using only an internal combustion engine powered with fossil fuels"[Fuhs, 2009; Thompson et al., 2011]. The continuous development of technology making the people optimistic to solve all emissions problems and Possible significant GHG emissions reduction [4].

Indirect environment effects of electric cars have been studied by many researchers such as the one in Romania that analyze the used energy and resources, the results show that although electric cars are considered zero emission, there are pollutions related to energy production and recycling procedures, the study measured the energy consumption of electric cars, which shows that Sox emissions in particular will increase, as a result of the using of electric cars, unless alternative and renewable energy sources are implemented in the future [4].

The percentage of electric vehicles among the total number of vehicles in the past surely not for the benefit of EV even at the moment the electric car market is still not one of the main ways of transportation, In general, the number of electric vehicles in the world is insignificant comparing of the total number of cars, that to say it is still kind of luxury, However, the positive prospects from different studies are optimistic and telling us that by 2020 electric vehicles will reach the number of over 10 million worldwide despite all above [5].

On the other hand, researchers for China vehicle emissions and how it increased rapidly in the last few years are used a prediction models to forecast the EV sales in short and long term period, the transportation sector through the spread of electric vehicles (EVs) is considered very significant in reducing air pollution and increasing energy security. in China, EV sales are recorded in two categories, battery EVs (BEVs) and plug-in Evs, plug-in hybrid electric vehicle (PHEV) the second category reducing the dependency on oil as a transportation fuel (since it derives some power from electricity and some from gasoline).

While the battery EVs is affected by many obstacles, such as high prices, the limited travel rate of batteries, and need special supporting infrastructure. Few studies for demand of EV are done to investigate the people intention toward EV, such studies for example in Malaysia they used survey and questionnaires while in US cities they used data collection from online survey, Predictions of the Chinese automobile sales made with regression using 'multivariate time series models even the univariate time-series model, which depicts the accurate tendency of EV sales, can be applied easily because only a few observations are required 'The results concluded that in the future there will be a significant demand for the BEV and PHEV in China [6]. 
another article that analyses the using electric instead of internal combustion engines in Republic of Slovenia shows that electric vehicles more efficient as well as it will reduce emission and improve urban environment by depending on the electrical energy source or other sources as planned for the future by using renewable energy which is necessary to control pollution," the greenhouse gases from transport in Slovenia increased from 1986 to 2012 by 185 \%" [S. MUHIČ et al.,2018]. It can be calculated the amount of electrical energy that will consumed by predicting the number of EV, also it has been predicted that the electric cars almost twice better efficiency than internal combustion engine cars [7].

Several of Hungary's studies are implemented for example the real number of electric cars in Hungary, its effect on the energy industry and how far does it worth the investment. Electric vehicles are now often featured in the Hungarian press and other professional publications, to announce for a new charging station or a new type of electric or plug-in vehicle points is spotted in the streets of Budapest meanwhile a few analyses are available to the future outlook and overview of electric vehicles in Hungary for example how many electric vehicles will be in the upcoming next years, the influence of electric mobility on the infrastructure, the charging station and the electric network and its effects on the Hungarian energy sector, energy companies, charging station manufacturers, maintainers and operators and economy,

"Study of indirect factors is not easy to quantify for example new development sources of infrastructure, expanding the domestic vehicle manufacturing capacity and the scope of suppliers, growth in products manufactured using related and non-related technologies, creating new jobs, strengthening and building international relationships etc." [Peter Gyenes, 2015] [8].

It is shown by statistics that emissions of electric vehicles will keep falling with decreasing percentage of electricity generated by coal power and continued improvements in vehicle technologies, so from optimistic point of view the EVs will become even cleaner as more use of renewable sources of energy such as wind and solar for electricity generation and will result in an over 25 percent reduction in emissions. Also in the future it is expected that the lithium-ion battery at the end when no longer used by cars could be used in other applications or parts of it recycled for use in new batteries, etc. (Retrieve Technologies 2015; Umicore 2015). The ability to recycle depends two things how the battery designed and the of recycling process itself. Recycling needed energy which will produce emissions and increase global warming, but this will be much less than using new materials [9].

An important aspect to be discussed is the charging/discharging points and its spread will be critical for the successful adoption of EV. Because of that issue and a lot more the general acceptance of EV faced several challenges which make the internal combustion engine ICE vehicles more preferable, these challenges including the short distance range of driving, the charging stations and the suitable infrastructure as well as other factors. Comprehensive researches should include different control and operation strategies, problems related to the energy management, centralized and decentralized charge control in addition to charge time [10]. 


\section{Transportation Sector in Jordan}

Jordan imported $96 \%$ of the total primary energy consumed from other countries. Throughout the years 2013 to 2018 as shown in the figure below the primary energy consumption by transportation sector is (50) \% of the total, Jordan is trying through the energy strategy to increase reliance on local sources, especially those derived from renewable energy [11].

In the recent years, electricity generation has been dependent on imported natural gas and recently some serious Procedures have been made to use solar and wind power

Jordan faced several challenges in the last 30 years:

Immigrations waves from neighbouring countries (Iraq, Syria, Yemen and other countries).

Infrastructure has been effected by the unexpected sudden increase in the population created up burden on infrastructure (water, transportation, energy, education, health, etc.), 2016 Statistics shows that number of people who entered the kingdom were 926658, following figure show the average annual population growth [12].

Currently as the number of cars increased rapidly because of population growth transportations couldn't meet that fast growth which leave us with current situation of high congestions, low safety procedures, high traffic accidents, as well as insufficient studies for sustainability dimension performance of transportation system, lack of modern developed transportation system and less cost effective public transportation modes, Figure 1. shows the population growth with time [13].

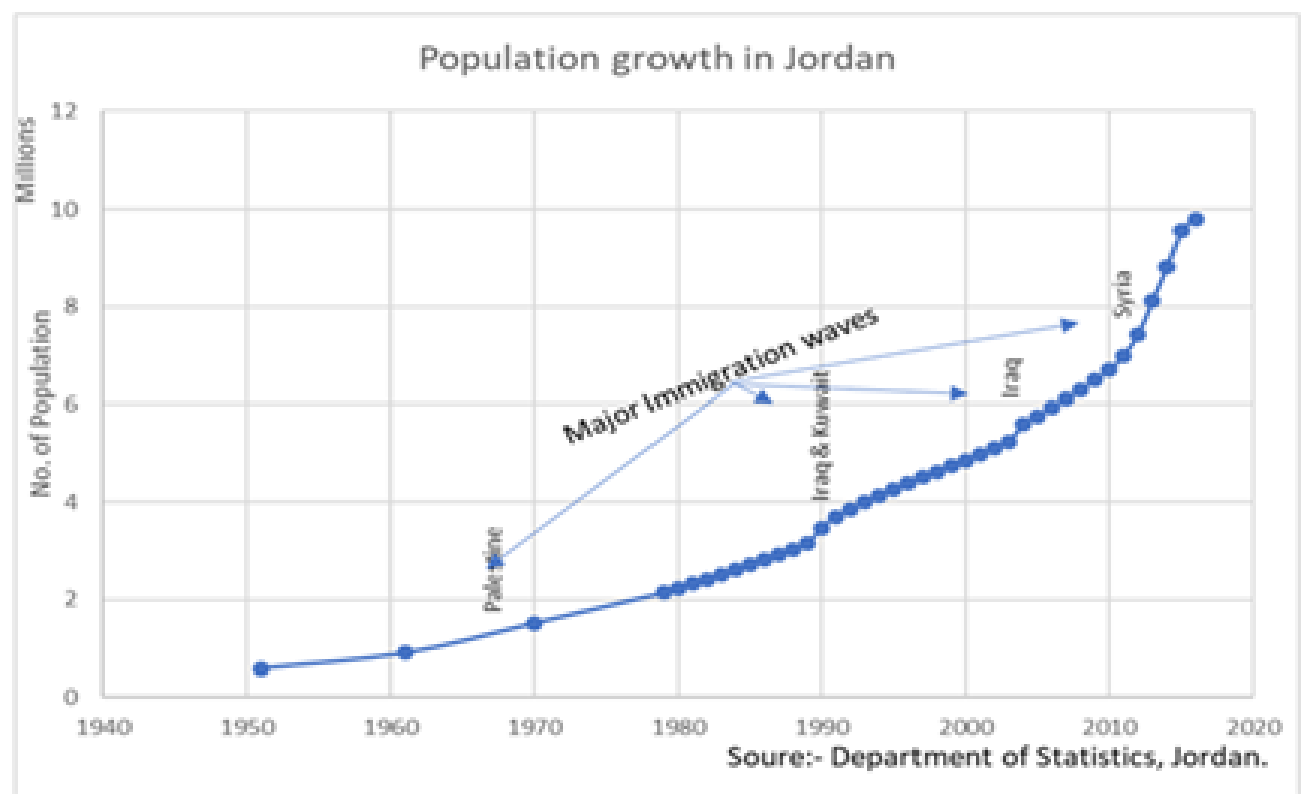

Figure 1. Population growth in Jordan

Figures 2. and 3. respectively represent the continuously increase in the number of passenger cars and the trend of the past three years showing the contribution of hybrid and electric cars compared to Internal combustion engine cars, in year 2018 the Jordanian government has introduced a new law to impose some taxes on hybrid cars, the customer response was immediate and the number of registered cars was almost zero, 
This shows how the legislations and policies can be effective in sustainability. The trend to buy hybrid and EV car in the last few years in Jordan is high, unfortunately there is no enough information available on number of vehicle based on fuel type [14].

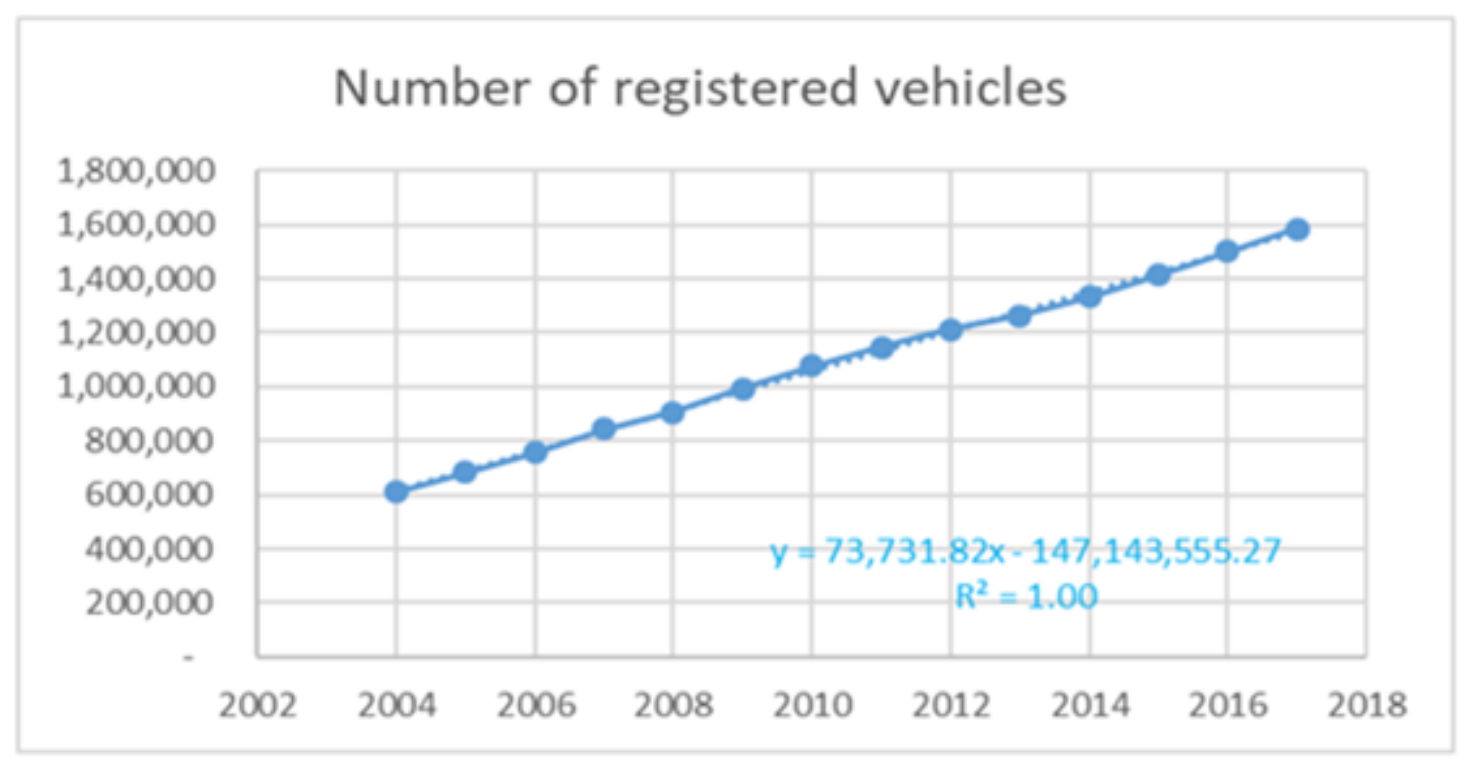

Figures 2. Number of registered vehicles

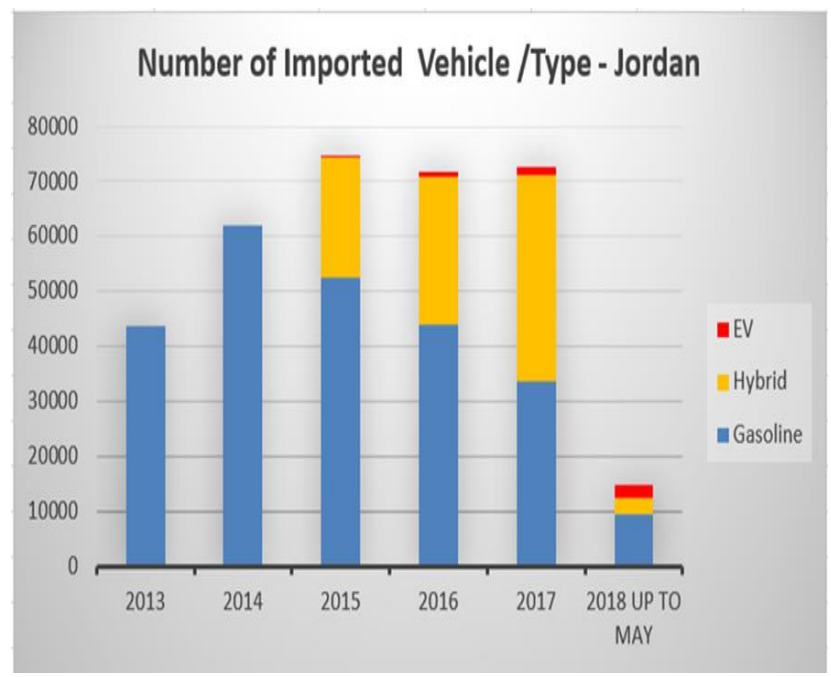

Figures 3. Number of imported vehicles for each type

Consumption trend for primary energy have the same trend in increasing in the last (27)years (19902018)energy consumption grows from (3) million equivalent ton (10) million ton Same as Population, it grows with the same trend. Figure 4. shows the increasing of energy consumption by transportation sector over time [15]. 


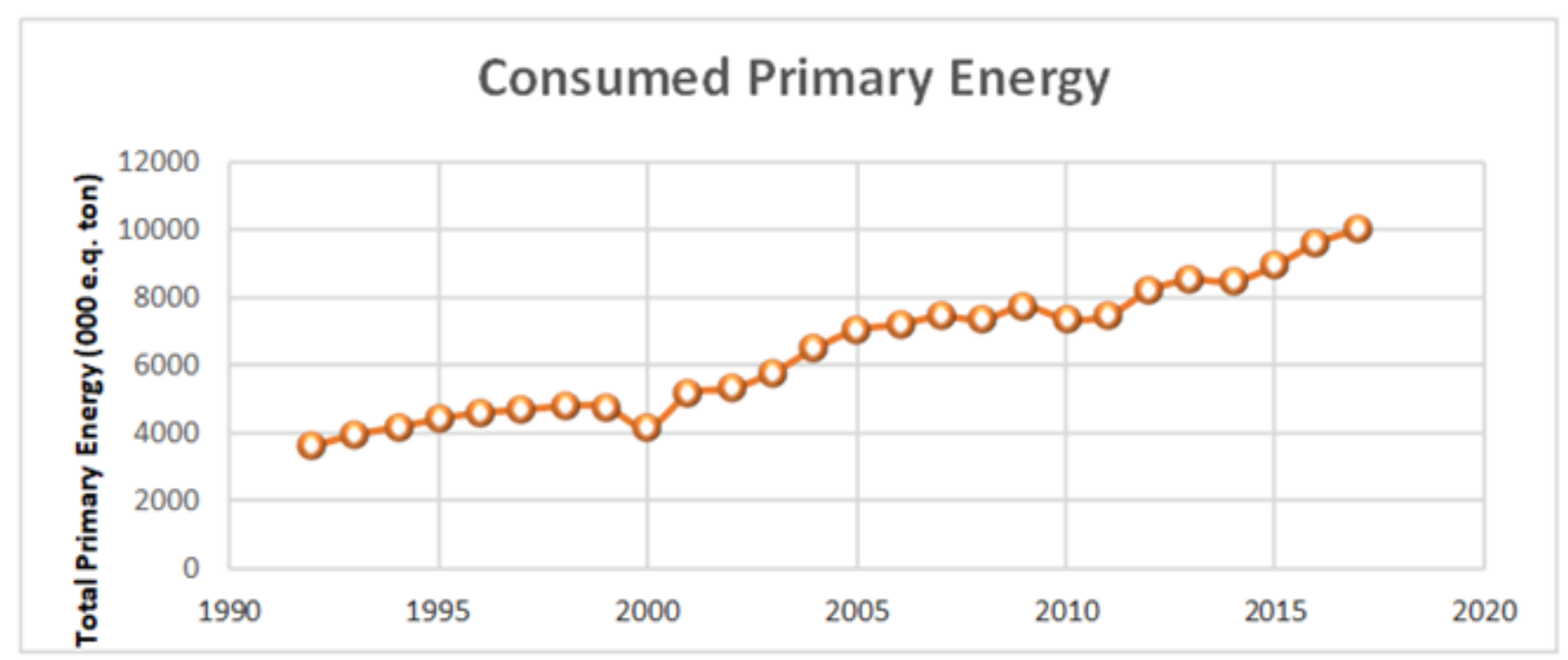

Figure 4. Consumed primary energy

\section{Methodology of Research}

To forecast the future, it is known that in the field of transportation, data analysis is probably the most important and widely used research tool for analysis the data collected from authorized Institutions and organizations, governmental and private sectors, published research, secondary sources such as, periodicals, articles, regional, local and international similar studies.

In addition, it is necessary to start theoretical assumptions through studying the base year and the forecasting of future demand of Vehicles mobility, energy and emissions in Jordan.

\section{Analyzing for Environmental Impacts}

Jordan Transport system is based on individual transport with almost absence in public transport system, the high growth rate of the number of vehicles go together with high growth of populations created a pressure on transportation sector in Jordan and causing a significant problems related to safety, economic, energy consumption and environment.

Sustainable mobility and the evaluation of sustainability in Jordan's transport sector in the analysis will focused on three main aspects:

- reduce emissions from transport sector (i.e. $\mathrm{CO} 2, \mathrm{PMx}, \mathrm{NOx}$ ),

- reduce energy consumption and since the new global trend of using efficient fuel engines which found an excellent acceptance in the Jordanian market is to be evaluated to measure if the future trend is sustainable.

- traffic reduction measured in terms of (V-km reduction) at national level and in densely populated areas 


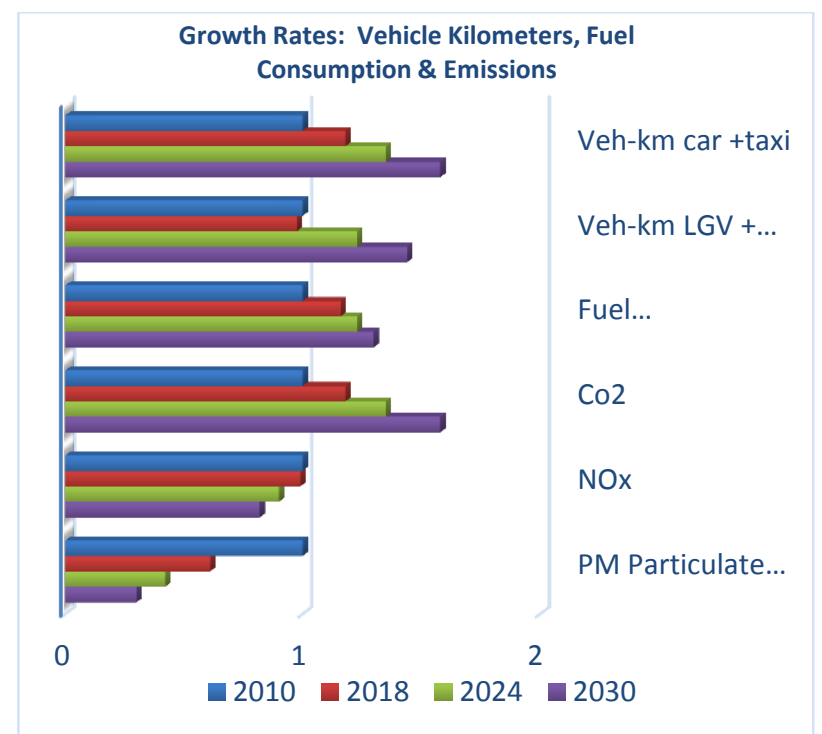

Figure 5. Growth rates, Vehicle kilometers, Fuel consumption and Emissions

As in figure 5. the bar chart shows that the vehicle kilometers in private transport expected to increase by $56 \%$ in the long term (2030), the fuel consumption will grow by approximately 30\%, CO2 emissions will show an increase by $26 \%$, and NOx emission decreases by $14 \%$ according to the transport model simulations.

It is difficult to predict the future growth in the number of vehicles because it is linked to the growth in population which is governed by geopolitical issues in the region, even though to make future prediction for the demand of the number of passenger's vehicles the curve behaved perfectly with the straight line regression with high R2 $=99.85 \%$ as shown in figure 6 . which represent the adoption of electric cars on sustainability, based on the global trend to replace Internal Combustion Engine vehicles (ICE) powered by fossil fuels by Electrical Vehicles (EV) [15]. following the increase of car and truck trips, air quality extremely affected in Jordan, particularly in urban areas. The Air Pollution Performance measures are VOC, Car on CO and NO, emissions and the Energy Use Performance measure is Fuel consumption [15].

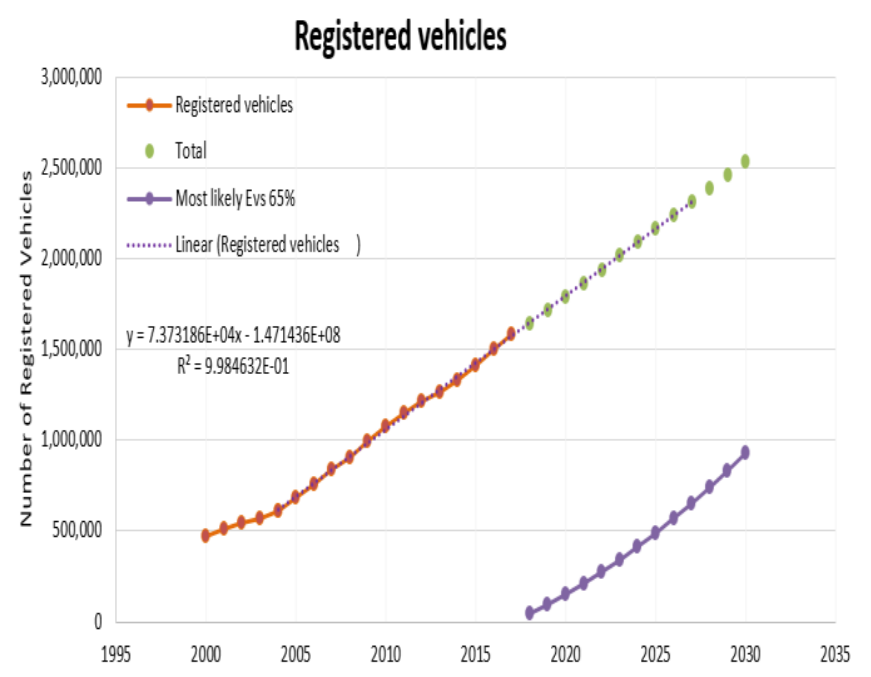

Figure 6. Future prediction for the demand of passenger's vehicles 


\section{Conclusions, future prediction and recommendation}

In this analysis transportation system will be evaluated with respect to sustainability, and mainly: -

- Primary energy consumption as total and contribution of transportation sector on consumption (Only gasoline fuel consumption will be considered since all of this quantity is used in transportation sector), and the effect of the sector on environment.

- To see the impact of energy consumption in the transportation sector when replace ICE with CV

The following prediction models as shown in Figures 7. and 8. are done as follows;

- Prediction models to forecast the increase in fuel consumption and electricity consumption with time.

- Gasoline consumption shows the historical and the future prediction best fit achieved by linear regression relationship with $\mathrm{R}^{2}=97 \%$.

The gasoline and electricity consumption forecasting models were made by using different scenarios to forecast the base situation as well as the different scenario assumptions for the future and the decrease in fuel consumption with time if $\mathrm{EV}$ is used to replace the ICE vehicles either partially or completely.

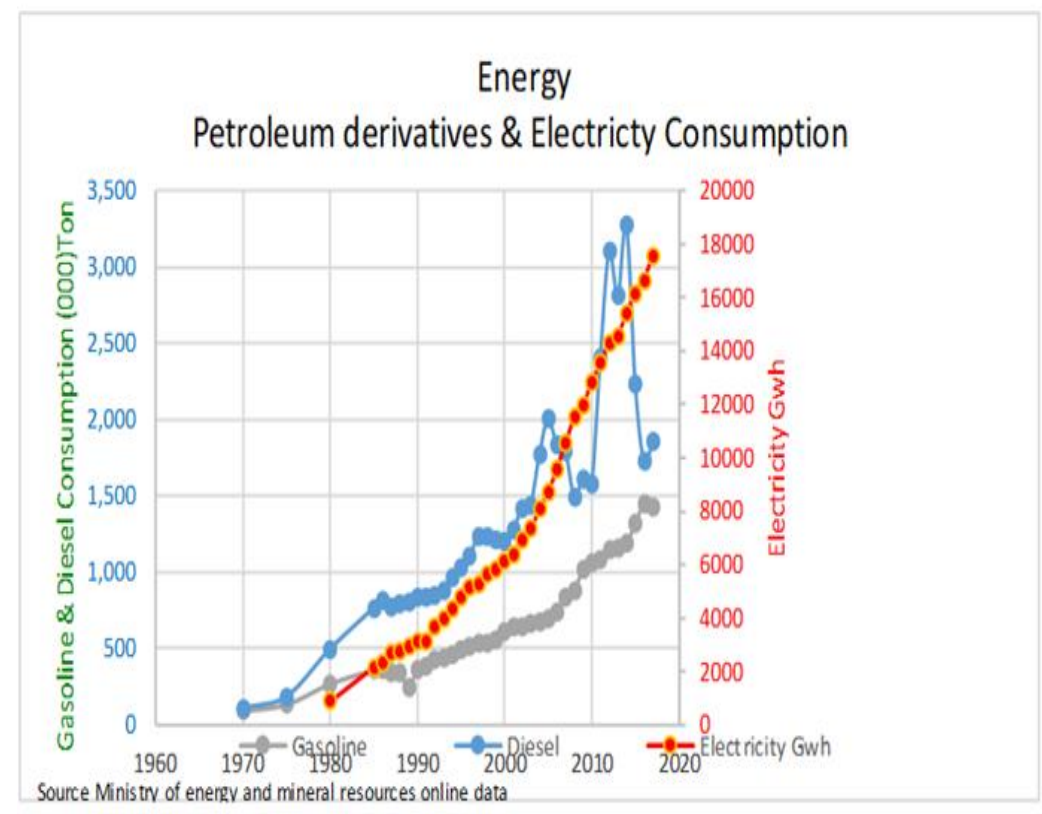

Figure 7. Energy forecasting for petroleum and electricity consumption 


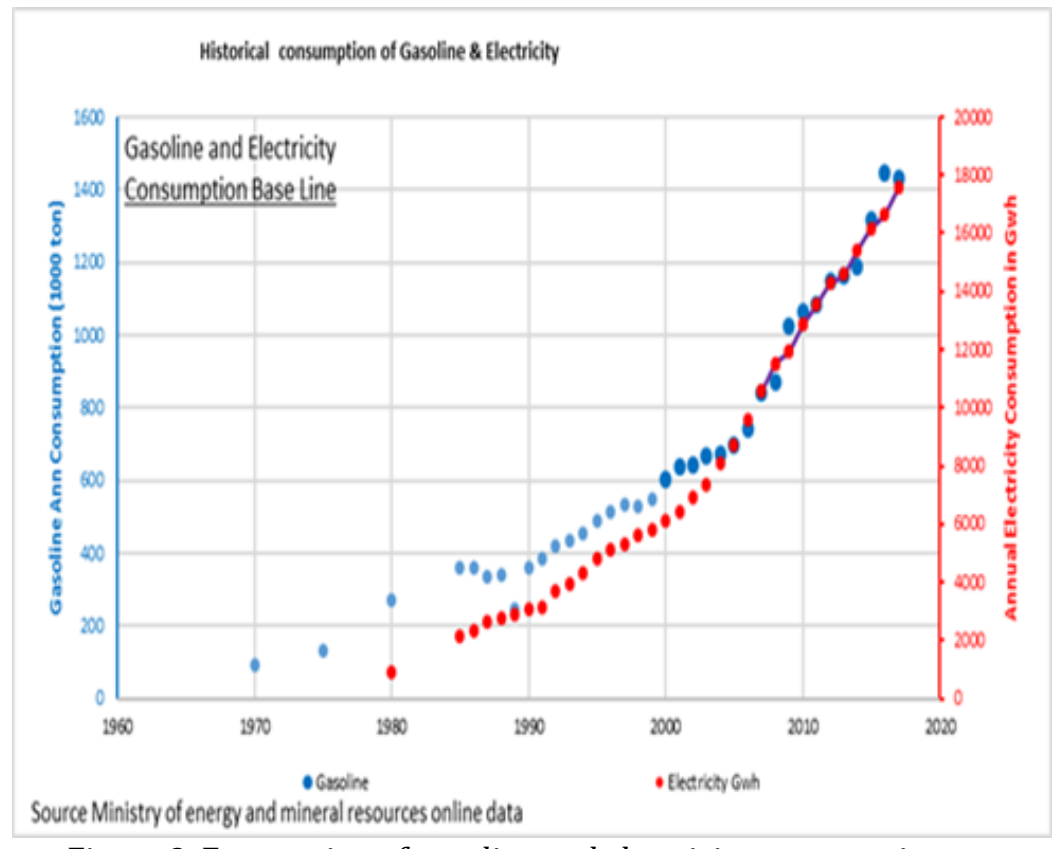

Figure 8. Forecasting of gasoline and electricity consumption

In order to meet the requirements of the social and economic development to road transport, we must keep road transport in a rapid development, but it will also bring many new problems, such as making the shortage of oil resources more serious and the emissions more severe, It can be concluded as shown in the figures that replacing the energy source by EV with significant percentage in the future would have a positive impact on emissions and could expect lower emissions and less harmful impact on the natural and urban environment

There is no doubt by starting implementation of the suggested solution there will be an impact on the present infrastructure since the current filling stations of gasoline and diesel will be affected and replaced gradually by electric charging points in the stations, in the parking areas and houses, The driving range and charging time which will cause changes in the style of (refuelling) /electric recharging, to be compatible with the period that required for refuelling / recharging and the frequently number of visits since there are serious limitations regarding the EVs battery capacity.

Not to mention the concern of indirect and direct environmental effects in the manufacturing operating and recycling of electric motor batteries through the life cycle of the cradle to the grave.

This issue will have a direct impact on gas station that will affect the revenue of such companies, also it will have a direct impact on labour since electric charging station is not a labour intensive in addition to the adverse impacts on the current car industry because EV manufacturing is not a labor intensive industry

\section{Acknowledgements}

I would like to acknowledge my supervisor as well as my family for their support, also I would like to acknowledge the reviewers and the organizers of Debrecen conference. 


\section{References}

[1] O.P. Van Vliet - T. Kruithof - W.C. Turkenburg - A.P. Faaij AP (2010) Techno economic Comparison of series hybrid, plug-in hybrid, fuel cellAnd regular cars. Journal of Power Sources 195 (19) pp. 6570-6585.

[2] A. Fricker (2001) Measuring up to Sustainability http://www.metafuture.org/articlesbycolleagues/AlanFricker/Measuring\%20up\%20to\%20Sus tain ability.htm accessed: 2010-12-01.

[3] T. Litmann (2009) Well Measured: Developing Indicators for Comprehensive and Sustainable Transport Planning, Victoria Transport Policy Institute December 2009 http://www.vtpi.org/wellmeas.pdf accessed, 2009-03-02.

[4] B. O. Varga - F. Mariasiu Automotive Engineering \& Transports Department, Indirect Environment-Related Effects of Electric Car Vehicles Use, Technical University of Cluj-Napoca, Automotive Engineering and Transports Department, 103- 105, Muncii Bd., Cluj-Napoca, Romania University of Iasi, Romania, *Technical University of Cluj-Napoca, 103-105 Muncii Bd., Cluj-Napoca, Romania

[5] Z.S. Gelmanova - G.G. Zhabalova - G.A. Sivyakova - O.N Lelikova - O.N. Onishchenko - A.A. Smailova - S.N. Kamarova (2018) Electric cars. Advantages and disadvantages. J. Phys.: Conf. Ser. 1015 052029, Karaganda State Industrial University, Temirtau, Kazakhstan, 30, Respubliki Ave.Temirtau, 101400, Kazakhstan, View the article online for updates and enhancem Email:ayzhana.smailova@mail.ru

[6] Y. Zhang - M. Zhong - N. Geng - Y. Jiang (2017) Forecasting electric vehicles sales with univariate and multivariate time series models: The case of China. PloS one, 12(5) e0176729.

[7] S. Muhič - A. Čikić - J. Pištan - M. Stojkov - M. Bošnjaković (2018) Transport emissions and electric mobility in private transport in the Republic of Slovenia. Tehnički glasnik, 12(2) pp. 98103.

[8] P. Gyenes (2015) E-mobility Outlook of Hungary. Engineering and Industry Series Volume Deregulated Electricity Market Issues in South Eastern Europe. pp.189-195. Available online at http://trivent-publishing.eu

[9] R. Nealer - D. Reichmuth - D. Anair (2015) Cleaner cars from cradle to grave: How electric cars beat gasoline cars on lifetime global warming emissions. Union of concerned scientists report.

[10] S. Faddel - A. Al-Awami - O. Mohammed (2018) Charge Control and Operation of Electric Vehicles in Power Grids: A Review. Energies. 11(4) 701.

[11] Ministry of energy and mineral Recourses-Jordan, http://www.memr.gov.jo

[12] Department of Statistics-Jordan, http://dosweb.dos.gov.jo and Annual statistical reports issued by the Jordanian Department of Statistics

[13] Central traffic department, https://www.psd.gov.jo/index.php/en /2016-08-24-07-0742/Traffic Institute, Jordan, Annual statistical reports for vehicles - Jordan,

[14] Drivers and Vehicles Licensing Department, https://www.google.com/search =Licensing of drivers and vehicles \&client

[15] Jordan Long Term National Transport Strategy and Action Plan, http://mot.gov.jo/Pages/viewpage.aspx page ID=59 